\title{
Bending Capacity of Orthogonal and Parallel Glulam T-section Beams
}

\author{
Jiejun Wang1,*, Tao Yang ${ }^{2}$, Fan Ning' and Zhenyu Rao ${ }^{1}$

 \\ ${ }^{2}$ Hualan Design (Group) Co., Ltd., Nanning 530000, China
}

Received 4 November 2019; Accepted 19 January 2020

\begin{abstract}
The bridge deck slab and the rectangular beam of the glued-wood beam bridge are connected by bolts and studs; thus, the joint surface is prone to slippage, and the beams and plates experience difficulty in bearing loadings together. This difficulty results in problems, such as stress concentration and screw corrosion and loosening, and weakens structural bearing capacity, stiffness, and integrity. In this study, an experimental model of glued timber T-section beams formed by gluing between bridge decks and rectangular beams and a calculation method for T-beam shear stress were proposed to improve the bearing capacity, stiffness, and integrity of the structure for ensuring that the bridge deck and the rectangular beam jointly bear stress. Three sets of beams, namely orthogonal T-beams, parallel T-beams, and rectangular beams were made using Larix gmelinii larch boards and structural glue to perform static bending bearing capacity test for examining the strain, deflection, and ultimate bearing capacity of the members and observe the destruction pattern. During the test, the bending shear strength was calculated following the principle of equivalent stiffness and the shear strength formula proposed by Rammer. Furthermore, a finite element model of glulam beams based on elastoplastic theory was established using structural analysis software. The displacement, strain, and failure mechanism of the members under the test loads were simulated and analysed using the model to verify the test results. Results demonstrate that, when the three types of beams are bent, they are sheared along the grain near the central axis of the section. The bonding surface between the wing plate and rib of the T-beam is undamaged, and the bonding is reliable with strong structural integrity. Compared with those of rectangular beams, the bearing capacity (limit load), bending stiffness, and ductility coefficient of the parallel T-beams are increased by $71 \%, 189 \%$, and $23 \%$, respectively. Compared with those of rectangular beams, the bearing capacity, bending stiffness, and ductility coefficient of the orthogonal T-beams are increased by $33 \%, 28 \%$, and $25 \%$, respectively. Compared with those of rectangular beams, the bearing capacity, bending stiffness, and ductility coefficient of the glulam T-beams are greatly improved. By considering the principle of equivalent stiffness and using the Rammer formula, the shear strength test values of orthogonal T-beams and rectangular beams of glulam deviate from the calculated values by $8.0 \%$ and $-5.6 \%$, respectively, which indicates good agreement. However, the shear strength test value of the parallel T-beams deviates from the calculated value by $19.2 \%$, which indicates slightly lower calculation accuracy. The finite element analysis is consistent with the results of the experiment. This study provides certain references for the engineering design of glulam T-beams.
\end{abstract}

Keywords: Glulam T-beam; Flexural bearing capacity; Longitudinal shear; Larch wood; Finite element

\section{Introduction}

Glulam is an environmentally friendly and renewable building material with advantages of light weight, good seismic performance, convenient processing and manufacturing, and low cost. In recent years, the development of China's tourism industry and the continuously increasing need for environmental protection have facilitated the use of modern plywood bridges in building construction, and related technical research has also made considerable progress [1].

Glulam beam bridge is the main type of pedestrian wooden structure corridor bridge because of its advantages of simple, economical, and beautiful structure and convenient industrial construction [2]. The bridge deck and the rectangular beam (longitudinal and cross beams) are connected by nails, which easily cause joint surface sliding; consequently, the bridge deck and the rectangular beam bear the loadings jointly with difficulty, which results in stress concentration and screw corrosion and loosening [3-4].

On the basis of the problems mentioned above, scholars have adopted various reinforcement methods to improve the flexural capacity and stiffness of glued wood beams and conducted numerous studies. However, the actual implementation of these enhancement methods is complicated and costly, which limits their application to date. Therefore, the bearing capacity, stiffness, and integrity of the beam bridge should be improved effectively while saving the cost.

Thus, a T-beam component under common stress is formed in this study by bonding the bridge deck and the rectangular beam to enhance the structural bearing capacity, stiffness, and integrity. Furthermore, an experimental study is presented to show the bending failure mechanism and the calculation formula of bearing capacity. Accordingly, a reference can be provided for practical engineering application. 


\section{State of the art}

To date, many scholars have conducted numerous studies on the mechanical properties of glued wood beams. Hiroshi Yoshihara [5] conducted shear tests on rectangular and Ishaped hemlock short beams with different depth-span ratios under different loading modes and verified the effectiveness of the test methods. However, the specific application scope of each test method was not proposed. Roberto Tomasi [6] analyzed the flexural capacity of glued timber beams by using the limit strain method based on the simplified bilinear or bifold constitutive model. However, this method ignores the elastoplastic characteristics of the compression zone. Rammer [7] studied the relationship among the size, bending strength, and shear strength of glulam beams and proposed an empirical formula for the shear strength of glulam rectangular beams, but this formula has limitations and is inapplicable to beams with large sizes. Cao Lei [8] explored the static bending and fatigue properties of rectangular beams from larch glued wood and presented the calculation formula for the rigidity degradation of glued wood beams. However, few test samples were used, and only the fatigue properties of larch glued wood were studied. Thus, the formula should be further modified using a large number of data through computer simulation analysis. Zhou Jiale [9] conducted tensile, compressive, and bending tests on glued wood specimens of larch and proposed the recommended strength design values of the glued wood of larch. However, the shear resistance, Poisson's ratio in different directions, and the development of plastic stage deformation should be considered to evaluate the mechanical properties of the wood under complex stress state, which requires further study. Klapalek P [10] studied the influence of the distribution of wood knots on the flexural strength of glulam beams by establishing the finite element model of glulam beams with knots. However, any optimization suggestions were not provided.

In recent years, European and American scholars have proposed a cross-laminated timber (CLT) made of solid wood sawn timber and structural adhesive. CLT has been widely used in bridge decks, floors, and wall structures because of its good mechanical properties, two-way strength, and light self-weight. Danielsson. H [11] proposed an improved method of calculating the internal force and stress distribution model related to three failure modes of CLT beams (i.e., total shear, net shear, and shear failures in the intersection area between adjacent longitudinal and transverse laminations), but the model also exhibits defects related to the assumption of internal force distribution. Sikora. K.S [12] studied the effect of laminated thickness on the bending and shears mechanical properties of CLT but did not provide the corresponding optimal method of blank assembly. On the basis of the orthogonality of CLT, Y Lu [13] deduced the calculation formula of interlaminar shear stress and measured the interlaminar shear strength of CLT hemlock with the short-span three-point bending method. However, the research and the analysis of rolling shear were insufficient. Gong. Y. C [14] used Japanese larch sawn timber with a depth-span ratio of 30 as raw material and tested the bending modulus and strength of CLT of threeand five-layer group billets by the four-point bending method. Given that the size considerably affected the mechanical properties of materials and the study only analyzed the bending performance of CLTs of the same size, the size effect on the bending resistance of CLTs requires further research.
Scholars have also investigated the use of other materials to enhance the performance of glulam beams and composite members. Soriano et al. [15] used rebar with two different ratios to reinforce laminated timber to reduce the inherent variability of timber and increase the ultimate bearing capacity of rectangular beams, but the beams of other sections were not studied. Yang. X. H [16] found that the deformation and bending capacities of members could be improved by pasting steel plates or adding screws at the bottom of the beam, but the effect of interlayer shear on the flexural performance of glulam beams was not analyzed in detail. Zhang. J [17] arranged parabolic prestressed tendons in the beam of glulam. The tests showed that the flexural capacity and stiffness of curved beams were increased more than those of straight beams. However, no method was proposed for calculating the ultimate load capacity of the corresponding glulam beam after strengthening. Szumigala et al. [18] carried out numerical analysis on the bearing capacity and rigidity of timber-concrete composite beam, but the connection performance between shear connection screws and wooden beams was not investigated. Chen. Q [19] conducted bending performance tests on bamboo-log composite beams and proposed the calculation formula of bending capacity. However, the influence of bamboo with different thicknesses on the bending performance of composite beams was ignored. McConnell [20] conducted bending test research on the glulam beam reinforced by linear prestressed reinforcement, but the influence of reinforcement ratio on the improvement in the bearing capacity of the glued wood beam was neglected. M.YahyaeiMoayyed [21] affixed aramid fibre-reinforced polymer composites to timber beams and investigated creep performances but did not propose the optimal thickness of the fiber material.

The above-mentioned studies mainly focus on examining the mechanical properties of laminated glulam beams, orthogonal glulam beams, glulam beams reinforcement, and composite members. However, research on the mechanical properties of glued wood beams with different cross sections, especially experimental research on the bending properties of T-section glued wood beams, is limited. In the current study, three groups of beams, namely, parallel glued wood T-beams, orthogonal glued wood T-beams, and rectangular beams, were made with the use of Chinese larch board and structural adhesive by gluing wing plates (bridge deck) and rectangular beams to form T-section beams. Through four static bending tests, the strain, deflection, and ultimate bearing capacity of the members were tested, and the damage form was observed. The finite element model of glulam beam was also established to perform elastic-plastic analysis and verify the test results. The failure mechanism and calculation formula of bearing capacity were also discussed to provide a reference for the engineering design of glued timber T-beam bridges.

The remainder of the study is organized as follows. Section 3 describes the test method and the establishment of the finite element model of glued wood T-beam. Section 4 presents the test results and analysis discussions. Section 5 summarizes this study and provides the relevant conclusions.

\section{Methodology}

\subsection{General framework}

Three groups (each group containing two test pieces) of glulam beams were made. The physical and mechanical 
properties of the materials are shown in Table 1. Group A (two test pieces): Parallel glulam T-beams, wood with wing and web (rectangular beam) in the same grain direction; Group B (two test pieces): Orthogonal glulam T-beams, wood with wing and web in vertical direction; Group C (two test pieces): Rectangular beam of glued wood. As shown in Fig. 1, the orthogonal and parallel T-beams have the same dimensions of $250 \mathrm{~cm} \times 25 \mathrm{~cm} \times 29 \mathrm{~cm}$ (length $\times$ width $\times$ height), with a depth-span ratio of $1 / 8$ and a shear-span ratio of 2.5. The T-beam was formed by gluing the wings and the web. The web had a size of $7.5 \mathrm{~cm} \times 24 \mathrm{~cm}$ (width $\times$ height) and was composed of 8 pieces of $7.5 \mathrm{~cm} \times 3 \mathrm{~cm}$ (width $\times$ thickness) boards that were glued in the same direction according to the direction of the wood grain. The size of the wings was $25 \mathrm{~cm} \times 5 \mathrm{~cm}$ (width $\times$ height), and the wings were made of two layers of $2.5 \mathrm{~cm}$-thick wooden boards glued together in the direction of the grain. The web size and blank assembling method of rectangular beams and T-beams were the same; the sizes were $250 \mathrm{~cm} \times 7.5 \mathrm{~cm} \times 24 \mathrm{~cm}$ (length $\times$ width $\times$ height), the depth-span ratio was $1 / 9$, and the shear-span ratio was 3.0. The physical and mechanical parameters of the wood were obtained by experiments, and those of the structural adhesive were provided by the manufacturer, as as shown in Table 1.

Table.1.Physical and mechanical properties of materials

\begin{tabular}{c|c|c|c|c|c|c}
\hline Materials & $\begin{array}{c}\text { Initial density } \\
\left(\mathrm{g} / \mathrm{cm}^{3} \mathbf{)}\right.\end{array}$ & $\begin{array}{c}\text { Moisture } \\
\text { content } \\
\mathbf{( \% )}\end{array}$ & $\begin{array}{c}\text { Tensile strength } \\
\mathbf{( M P a )}\end{array}$ & $\begin{array}{c}\text { Compressive } \\
\text { strength } \\
\mathbf{( M P a}\end{array}$ & $\begin{array}{c}\text { Flexural strength } \\
\mathbf{( M P a )}\end{array}$ & $\begin{array}{c}\text { Elastic Modulus } \\
\mathbf{( M P a )}\end{array}$ \\
\hline $\begin{array}{c}\text { Larix gmelinii } \\
\begin{array}{c}\text { Polyurethane structural } \\
\text { adhesive }\end{array}\end{array}$ & 0.66 & 14.87 & 128.68 & 42.04 & 86.23 & 10300 \\
\hline
\end{tabular}

\subsection{Bend property test}

The bending test device is shown in Fig 1. The calculated span of the glulam beam was $l_{0}=220 \mathrm{~cm}$, and the load was exerted at three points. A tripod was used to fix the two sides of the web to prevent lateral instability. Five dial indicators were installed on the foundation support, distribution beam support, and span. The top of the distribution beam was equipped with a $20 \mathrm{t}$ pressure sensor and jacked. Five strain gauges were uniformly arranged at the top of the middle wing plate of the T-beam span; two strain gauges were symmetrically arranged at the top (at the junction with the wing plate), middle, and bottom of the web plate; and one strain gauge was arranged at one side of the neutral axis web plate of the T-beam, with a total of 12 strain measuring points. The rectangular beam was symmetrical and evenly distributed with 5 strain gauges in the middle of the span and 10 strain measuring points in total. During loading, the deflection, ultimate load, and mid-span section strain (longitudinal strain) of each member were measured. All measurement data were collected synchronously by the TST3826 static strain test system by using the hierarchical loading method.

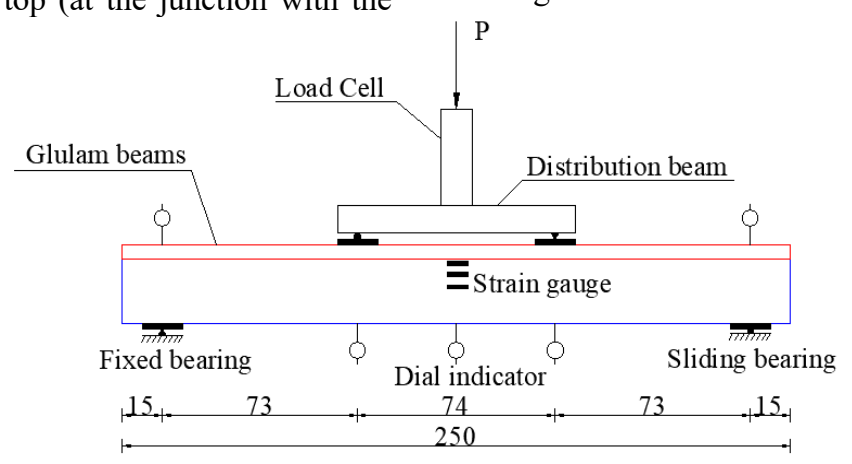

(a)

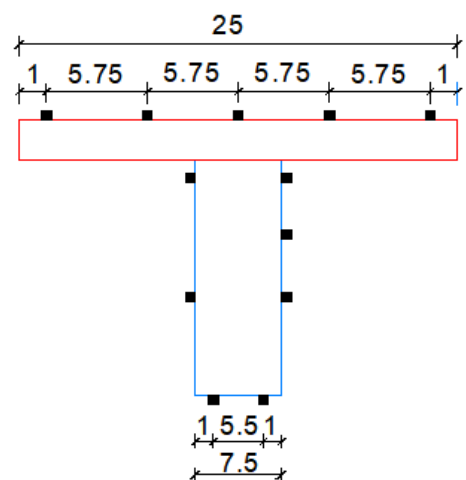

(b)



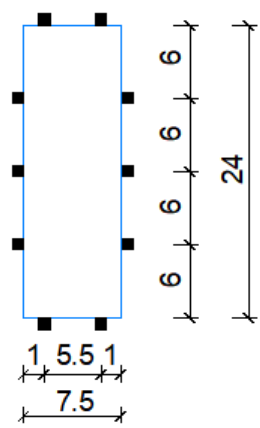

(c) 


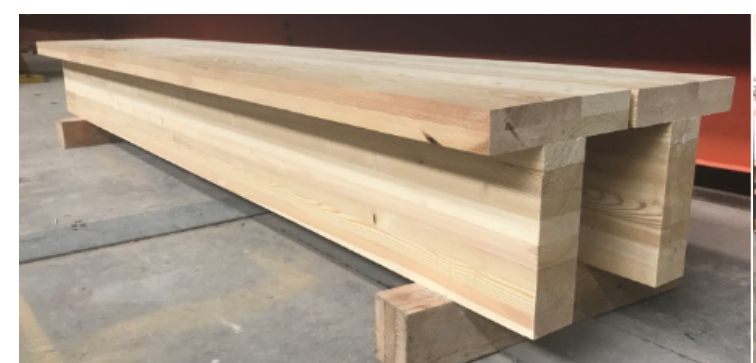

(d)

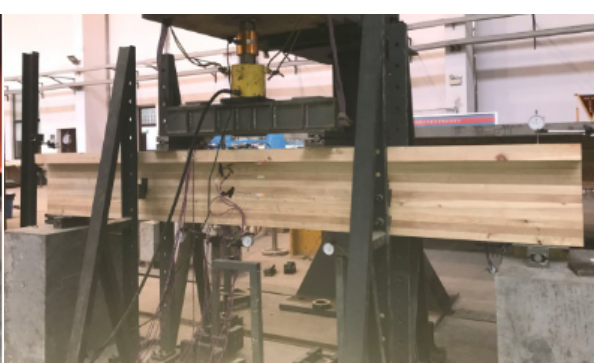

(e)

Fig. 1. Test loading and test point arrangement (Unit: $\mathrm{cm}$ ). (a) Specimen loading arrangement. (b) Strain measuring points at the mid span section of T-beam. (c) Strain measuring points at the middle section of rectangular beam span. (d) T-beam specimen. (e) Test device

\subsection{Calculation of shear strength}

For glulam beams with large depth-span ratios and small shear-span ratios, shear failure along the grain usually occurs when they are bent. At this time, the bending capacity of the wood beams can be determined by their shear strength

The shear stress (Fig. 2) at the section of the glulam beam can be calculated using Equation (1):

$\tau=\frac{F_{S} S_{Z}}{I_{Z} d_{1}}$

In this equation,

$F_{S}$ - Shear force on the cross section; its value is $P_{c} / 2$ with $P_{c}$ as the test load value;
$S_{Z}$ - Static moment at the section with respect to neutral axis;

$I_{Z}$-Moment of inertia of the entire section with respect to the neutral axis;

$d_{1}$-Thickness of T-beam web or width of rectangular beam.

According to the reciprocal theorem of shear stress, the shear stress $\tau^{\prime}$ in the horizontal direction (along the grain direction) is equal to the vertical shear stress $\tau$.

The shear stress $\mathrm{P}$ of the T-beam and rectangular beam sections maximizes at the neutral axis $\mathrm{Z}$ (the distance from the bottom of the beam is y). When it reaches the grain shear strength of the beam, the beam is shear cracked.



(a)

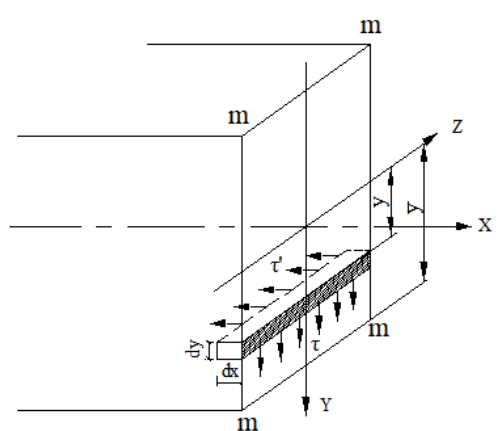

(b)

Fig. 2. Schematic of shear stress calculation of wooden beam section. (a) Facade of wooden beams. (b) m-m section

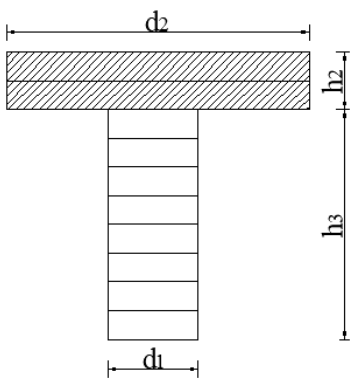

Orthogonal T-beam

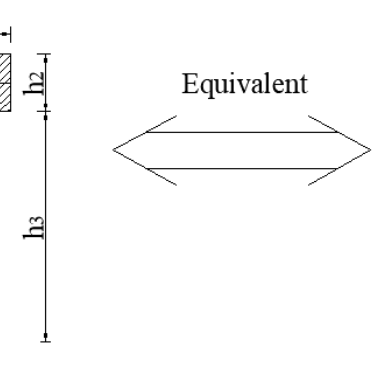

Fig. 3. Orthogonal beams are equivalent to parallel beams

An orthogonal glulam T-beam is equivalent to a parallel beam according to the principle of equivalent stiffness because of the different material elastic moduli of wing and rib plate sections (Fig. 3). Considering a constant section height, the width of the equivalent rear flange is calculated using the following equation:

$d_{3}=d_{2} E_{2} / E_{1}$

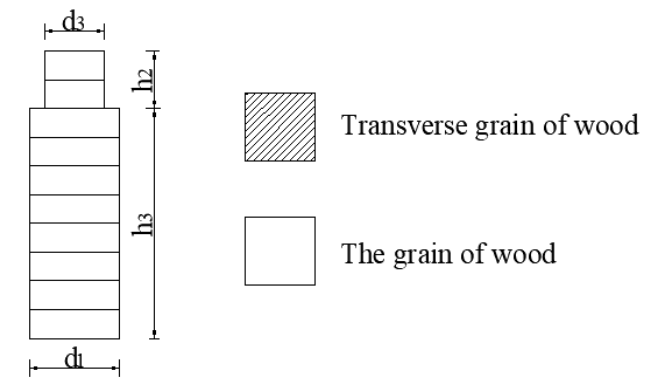

Parallel T-beam
In the equation:

$d_{2}, d_{3}-d_{2}$ is the flange width of the orthogonal and equivalent parallel beams, and $d_{3}$ is the calculated equivalent parallel beam flange with a width of $25 \mathrm{~mm}$. 
$E_{1}, E_{2}-E_{1}$ is the flexural elastic modulus of the wood along the grain, and $E_{2}$ is the flexural elastic modulus in the transverse direction.

The shear strength of glulam beams has the same size effect as other materials, which gradually decreases with the increase in cross-sectional area or volume. Rammer [7] proposed the following equation for calculating the shear strength of rectangular cross-section beams:

$\tau_{b}=\frac{1.3 k \tau_{m}}{A^{\frac{1}{5}}}$

In the formula:

$\tau_{b}$ - Shear strength of glulam beams;

$k$-Adjusted stress concentration factor for actual damage strength of wood; its value is 2 ;

$\tau_{m}$ - Shear strength of wood along grain; its value is 9.0 $\mathrm{MPa}$;

$A$-Effective shear area of wood beam can be calculated according to the relevant formula of material mechanics.

Parallel T-beam:

$$
A=d_{1} \times\left(h_{1}+h_{2}\right)
$$

OrthogonalT-beam:

$$
A=d_{1} \times h_{1}+d_{3} \times h_{2}
$$

Rectangular beam:

$$
A=d_{1} \times h_{1} \times 5 / 6
$$

In the equations, the mean of $d_{1}, d_{2}, d_{3}, h_{1}$, and $h_{2}$ can be found in Fig. 3.

\subsection{Finite element simulation analysis}

(1) Establishment of finite element model

A 3D solid element called C3D8R (eight-node hexahedron linear reduction integral element) was used to establish the analysis model of glued wood beam on the basis of the ABAQUS software (Fig. 4). The mesh size was divided into cubes with a side length of $3 \mathrm{~cm}$, and the longitudinal, transverse, and vertical directions were $\mathrm{X}, \mathrm{Y}$, and $\mathrm{Z}$ axes, respectively.

The mass density of wood was $0.67 \mathrm{~g} / \mathrm{cm}^{3}$. The size of the two steel plates used for loading the beam top was $15 \mathrm{~cm}$ $\times 25 \mathrm{~cm} \times 2 \mathrm{~cm}$ (length $\times$ width $\times$ thickness), the size of the steel plates of the beam end support was $20 \mathrm{~cm} \times 7.5 \mathrm{~cm} \times 3$ cm (length $\times$ width $\times$ thickness), and the steel parameters were as follows: the mass density was $7.8 \mathrm{~g} / \mathrm{cm} 3$, the elastic modulus was $2.1 \times 10^{5} \mathrm{Mpa}$, and the Poisson's ratio was 0.3 . The boundary conditions were as follows: the beam end bearing was simply supported, and the rigid connection between the steel plate and the glulam ignored the slipping between the steel plate and the glulam. The applied load value was the average value of the ultimate load during the glulam beam test, and the load increased linearly with time.

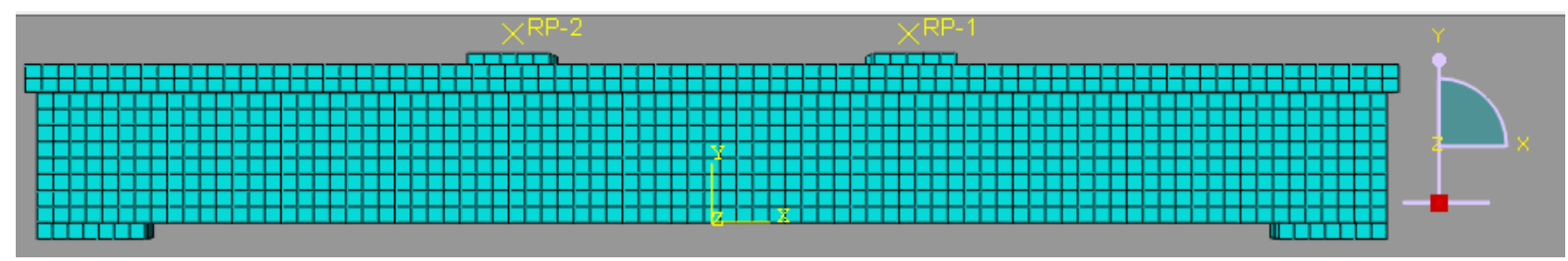

Fig. 4. Finite element model of glulam T-beam

\section{(2) Constitutive relationship}

We assumed that the glulam beam was an orthotropic elastoplastic model, and the effects of wood defects and the adhesive layers were ignored. The elastoplastic constitutive relationship with the same ideality of tension and compression was adopted (Fig. 5), and the expression is shown in Equation (7).

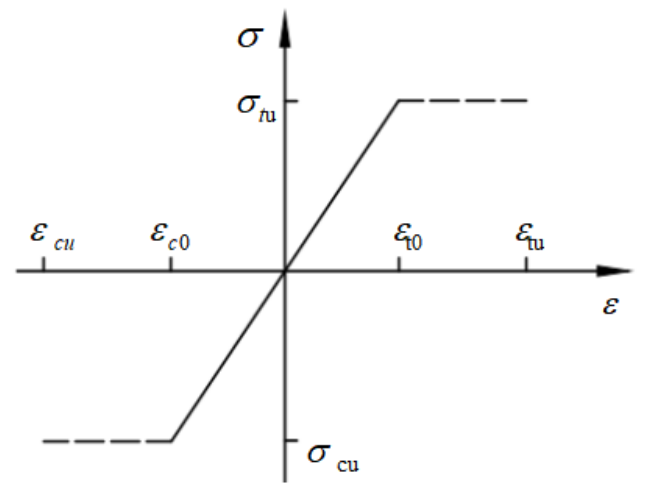

Fig. 5. Ideal elastoplastic constitutive relationship

$$
\sigma= \begin{cases}E \varepsilon & \varepsilon_{c 0} \leq \varepsilon \leq \varepsilon_{t 0} \\ \sigma_{c u} & \varepsilon_{c 0} \leq \varepsilon \leq \varepsilon_{c u} \\ \sigma_{t u} & \varepsilon_{t 0} \leq \varepsilon \leq \varepsilon_{t u}\end{cases}
$$

In the Equation:

$\sigma$-Stress of the wood;

$E$-Elastic modulus of wood;

$\varepsilon$ - Strain of wood;

$\sigma_{c u}, \sigma_{t u}-\sigma_{c u}$ is the yield compressive stress, and $\sigma_{t u}$ is the yield tensile stress;

$\varepsilon_{c 0}, \varepsilon_{t 0}, \varepsilon_{c u}, \varepsilon_{t u}-$ Yield compressive, yield tensile, ultimate compressive, and ultimate tensile strains.

\section{(3) Elastic parameters of wood}

According to the test results of this study and the reference to the 《Wood Structure Design Manual》[22], the material parameters for the elastic stage of Larix gmelinii in China are shown in Table 2. Among them, indexes L, R, and $\mathrm{T}$ indicate the longitudinal, radial, and transverse directions of the wood grain, and the same notations apply hereinafter. 
(4) Analysis of the characteristics of wood's plasticity stage

The commonly-used Hill strength criterion was used to analyze the elastoplastic behavior. We let axes 1,2 , and 3 be the longitudinal, radial, and chord directions of the material, respectively. The equivalent stress function of Hill's potential function of orthotropic wood is shown in Equation (8).

Table 2. Material properties of Larix gmelinii in elastic stage

\begin{tabular}{|c|c|c|c|c|c|c|c|c|c|c|c|c|}
\hline \multirow{3}{*}{$\begin{array}{c}\text { Elastic } \\
\text { constant } \\
\text { Value }\end{array}$} & \multicolumn{3}{|c|}{ Elastic Modulus(Mpa) } & \multicolumn{6}{|c|}{ Poisson's ratio } & \multicolumn{3}{|c|}{ Shear modulus (Mpa) } \\
\hline & $E_{L}$ & $E_{R}$ & $E_{T}$ & $\mathrm{v}_{\mathrm{LR}}$ & $\mathrm{V}_{\mathrm{RL}}$ & $\mathrm{v}_{\mathrm{LT}}$ & $\mathrm{v}_{\mathrm{TL}}$ & $\mathrm{V}_{\mathrm{RT}}$ & $\mathrm{V}_{\mathrm{TR}}$ & $G_{L R}$ & $G_{R T}$ & $G_{L T}$ \\
\hline & 16900 & 1690 & 845 & 0.36 & 0.06 & 0.48 & 0.04 & 0.53 & 0.05 & 1268 & 304 & 1014 \\
\hline
\end{tabular}

Table 3. Parameters of material yield stress ratio in all directions

\begin{tabular}{c|c|c|c|c|c|c}
\hline Yield stress ratio & $R_{11}$ & $R_{22}$ & $R_{33}$ & $R_{12}$ & $R_{13}$ & $R_{23}$ \\
\hline Value & 1.000 & 0.836 & 0.777 & 0.986 & 0.816 & 0.816 \\
\hline
\end{tabular}

$$
f(\sigma)=\sqrt{F\left(\sigma_{22}-\sigma_{33}\right)^{2}+G\left(\sigma_{33}-\sigma_{11}\right)+H\left(\sigma_{11}-\sigma_{22}\right)^{2}+2 L \sigma_{23}{ }^{2}+2 M \sigma_{31}^{2}+2 N \sigma_{12}}
$$

$\mathrm{F}, \mathrm{G}, \mathrm{H}, \mathrm{L}, \mathrm{M}$, and $\mathrm{N}$ are the constants related to materials, which can be obtained through experiments:

$$
\begin{aligned}
& F=\frac{\left(\sigma^{0}\right)^{2}}{2}\left(\frac{1}{{\overline{\sigma_{22}}}^{2}}+\frac{1}{{\overline{\sigma_{33}}}^{2}}-\frac{1}{\bar{\sigma}_{22}{ }^{2}}\right)=\frac{1}{2}\left(\frac{1}{{R_{22}}^{2}}+\frac{1}{{R_{33}}^{2}}-\frac{1}{{R_{11}}^{2}}\right) \\
& G=\frac{\left(\sigma^{0}\right)^{2}}{2}\left(\frac{1}{\bar{\sigma}_{33}{ }^{2}}+\frac{1}{{\overline{\sigma_{11}}}^{2}}-\frac{1}{\bar{\sigma}_{22}{ }^{2}}\right)=\frac{1}{2}\left(\frac{1}{{R_{33}}^{2}}+\frac{1}{{R_{11}}^{2}}-\frac{1}{{R_{22}}^{2}}\right) \\
& H=\frac{\left(\sigma^{0}\right)^{2}}{2}\left(\frac{1}{{\overline{\sigma_{11}}}^{2}}+\frac{1}{\overline{\bar{\sigma}}_{22}{ }^{2}}-\frac{1}{\bar{\sigma}_{33}{ }^{2}}\right)=\frac{1}{2}\left(\frac{1}{{R_{11}{ }^{2}}^{2}}+\frac{1}{{R_{22}}^{2}}-\frac{1}{{R_{33}}^{2}}\right) \\
& L=\frac{3}{2}\left(\frac{\tau^{0}}{\bar{\sigma}_{23}}\right)^{2}=\frac{3}{2 R_{23}{ }^{2}} \\
& M=\frac{3}{2}\left(\frac{\tau^{0}}{\bar{\sigma}_{13}}\right)^{2}=\frac{3}{2 R_{13}^{2}} \\
& N=\frac{3}{2}\left(\frac{\tau^{0}}{\bar{\sigma}_{12}}\right)^{2}=\frac{3}{2 R_{12}^{2}}
\end{aligned}
$$

In the Equation: values;

$\sigma_{i j}, \bar{\sigma}_{i j}$-Actual yield stress (true) and nominal stress

$$
\sigma_{0} \text { — Nominal compressive plastic yield point stress of }
$$
wood;

$$
\tau^{0} \text { - Shear stress at plastic yield point; its value is } \frac{\tau^{0}}{\sqrt{3}} \text {. }
$$$$
R_{11}, R_{22}, R_{33}, R_{12}, R_{13} \text {, and } R_{23} \text {-ratios of anisotropic }
$$

yield stresses in the axial direction. Their values are $\frac{\bar{\sigma}_{11}}{\sigma_{0}}$, $\frac{\bar{\sigma}_{22}}{\sigma_{0}}, \frac{\bar{\sigma}_{33}}{\sigma_{0}}, \frac{\bar{\sigma}_{12}}{\sigma_{0}}, \frac{\bar{\sigma}_{13}}{\sigma_{0}}$, and $\frac{\bar{\sigma}_{23}}{\sigma_{0}}$, respectively. In this study, the experiment data from the research work of Zhou Jiale [9] were used to define the material's isotropic yield stress ratio parameters, as shown in Table 3.

\section{Result analysis and discussion}

4.1 Mechanism Analysis of glulam beams' failure form Through the bending test of the glulam beam, the failure mode is shown in Fig. 6. In the test, except for the $\mathrm{C} 1$ member, which is damaged by the tensile force of the timber at the bottom of the beam, the five other members are sheared along the grain near the central axis of the ribs (on the lower side). Initially, the beam is in the elastic working stage. When the load increases to approximately $80 \%$ of the ultimate load, the wooden beam emits a crisp sound, and a visible initial crack appears in the middle of the beam rib at the loading position. As the load continues to increase, the wooden beam produces a deep, dense sound. The initial crack gradually expands toward the mid-span and penetrates, and the beam is severely deflected. When the ultimate damage load is reached, with a sudden loud noise, a long vertical longitudinal crack appears near the central axis of the rib beam. The crack then quickly expands to the beam end. The glued surface between the wing plate and the web of the T-beam does not fail. The morphology of cracks when the specimens broke is described as follows:

A1 parallel beam: longitudinally horizontal through cracks below the central axis of the mid-section cross section (Fig. 6(a)), A2 parallel beams: longitudinally horizontal through cracks across the central axis of the mid-section cross section, the beam end cross section cracks, and the support is partially in compression (Fig. 6 (b)).

B1 orthogonal beam: crosses the crack longitudinally and horizontally under the central axis of the cross section of the middle section, and one end slopes downward to the end of the beam (Fig. 6(c)); B2 orthogonal beam: crack development is the same as that of the B1 specimen, but the slope of the crack curve toward the beam end is slightly gentle (Fig. 6 (d)).

$\mathrm{C} 1$ rectangular beam: timber at the bottom of the midspan is damaged by tensile and degumming (Fig. 6(e)); C2 rectangular beam: longitudinally penetrates the crack horizontally across the lower part of the central axis of the mid-section, and one end extends substantially horizontally to the beam end while local buckling of the wood occurs (Fig. 6(f)).

Mechanism analysis: The tensile and compressive strengths of the wood along the grain direction are high and the shear strength is low. Meanwhile, when the height of the glulam beam in this test is large (greater than 1/10) and the shear span is small (less than 3.0), its bending resistance is stronger than the shear resistance. The shear stress near the neutral axis of the cross section of the beam at the two 
loading positions is the highest. When the stress exceeds the shear limit strength of the wood grain, shear failure will occur, which will produce initial cracks on the beam. With the increase in the loading magnitude, the initial cracks extend into the mid span. As the load continues to increase, the cracks extend to the beam end, and the wooden beam is damaged. The shear cracks are located on the lower side (tensile side) of the central axis of the section, and the cracks across the middle section show a horizontal trend, which are approximately $0-2 \mathrm{~cm}$ from the neutral axis. The cracks from the load section to the beam end section show a downward or horizontal curve, which are approximately 3 $\mathrm{cm}$. Most of the crack curve is inside the laminate, while a small part is on the cement surface. The shear fracture distribution is shown in Fig. 6(g).

The shear crack locates below the central axis of the section because the tensile strength of the wood along the grain is higher than the compressive strength. When the beam is flexed, the top timber yielded before the bottom timber is subjected to tensile yield. The position of the shear stress also moves downward. Thus, the shear stress maximizes on the lower side of the initial central axis of the beam section. The top and bottom surfaces of the glulam beams are not compressed or pulled to break. Even if the flange plate is a transversely orthogonal T-beam, it is also a ribbed plate shear failure. The $\mathrm{C} 1$ rectangular beam starts when the lower edge of the wood is damaged by tensile fracture. Owing to local defects in the knots, the tensile strength of the wood is reduced. The buckling of A2, C2, and other test specimens at the support and the loading plate compression is caused by excessive local stress. In summary, the results of the flexural test of glulam beams show that the shear failure of wood is along the middle of the beam rib section.
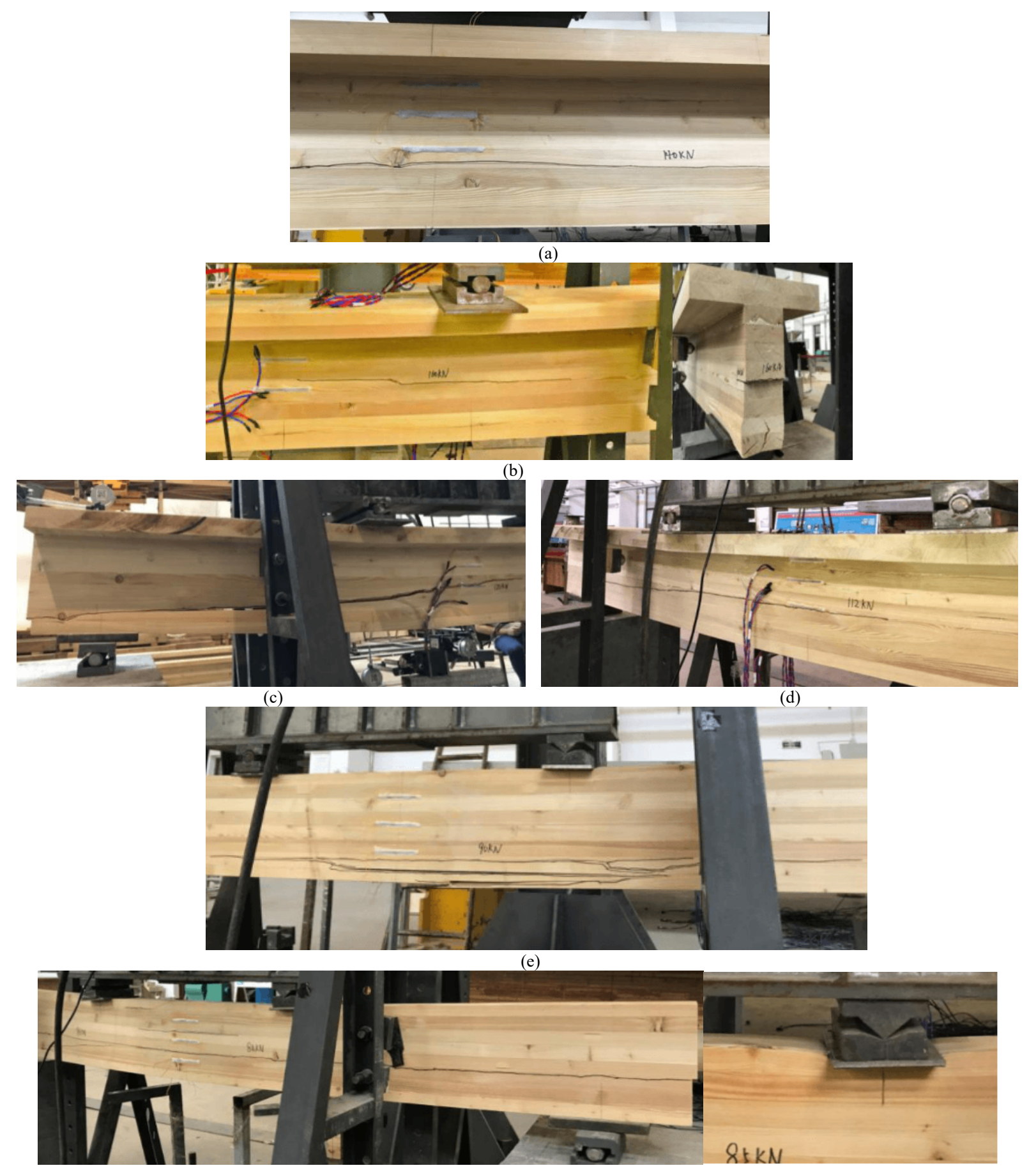

(f) 


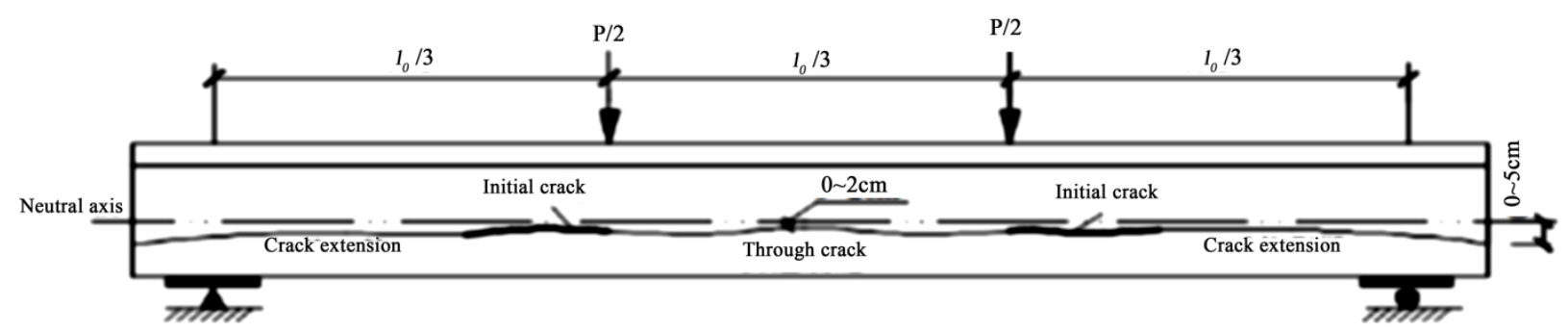

$(\mathrm{g})$

Fig. 6. Failure patterns of glulam beams.(a) A1 specimen shear crack. (b) Shear crack, beam end displacement, and local buckling at the support of A2 specimen. (c) Shear crack of B1 specimen. (d) Shear crack of B2 specimen. (e) Tension and degumming damage to the bottom of the beam of C1 specimen. (f) Shear crack and local buckling at loading plate of $\mathrm{C} 2$ specimen. (g) Development of flexural shear cracks in glulam beams.

\subsection{Load-deflection curve}

The test load-deflection curve of each test piece is shown in Fig. 7. The figure shows that the load-deflection curves of $\mathrm{A} 1$ and $\mathrm{A} 2, \mathrm{~B} 1$ and $\mathrm{B} 2$, and $\mathrm{C} 1$ and $\mathrm{C} 2$ in each group differ slightly with each other and show a bilinear change. The bearing capacity and stiffness of Group A (parallel T-beams) are greater than those of Group B (orthogonal T-beams), and the bearing capacity and stiffness of Group $\mathrm{C}$ (rectangular beams) are the smallest. Fig. 7 presents the test load-span deflection curve.

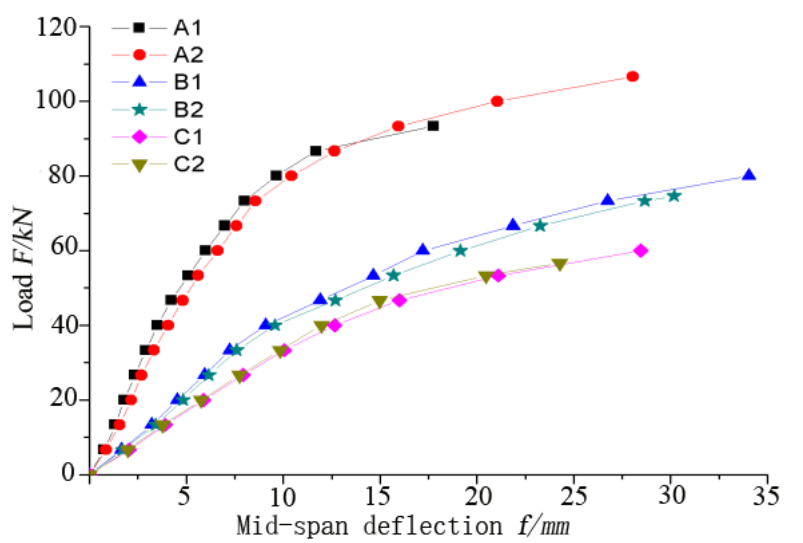

Fig. 7. Test load-span deflection curve

\subsection{Load-strain curve}

Five strain measuring points (Fig. 1) were arranged along the vertical height of the mid-section of the plywood T-beam and rectangular beam, and they were numbered 1 to 5 from top to bottom. The test load-longitudinal strain curve is shown in Fig. 8. A negative sign indicates pressure, and a positive sign indicates tension.

Fig. 8 indicates that the load-strain curve of the glued wood beam in the elastic stage follows a linear distribution. When entering the plastic stage, the increase in the compressive stress of the wood fiber gradually decreases, while the tensile side stress and strain remain linear, and the compressive yield point is significantly lower than the tensile yield point.

\subsection{Test results of main mechanical indicators}

The yield point is defined as the time when the compression zone of the section of glulam beams begins to enter the plastic phase. The mechanical indexes of the six glulam beam specimens obtained through the test are shown in Table.4, and the average values of the main test results of each group are shown in Table 5 . In the table, $\bar{a}$ represents the average values of the corresponding results of A1 and A2 specimens, $\bar{b}$ represents $\mathrm{B} 1$ and the average value of the corresponding results of $\mathrm{B} 2$ test piece, and $\bar{c}$ represents the average value of the corresponding results of $\mathrm{C} 1$ and $\mathrm{C} 2$ test pieces. Table 5 shows that the parallel T-beams have a $71 \%$ higher load capacity (limit load), a 189\% higher bending stiffness, and a $23 \%$ higher ductility than rectangular beams. Orthogonal T-beams have higher load capacity, flexural rigidity, and ductility coefficient than rectangular beams by $33 \%$, 28\%, and 25\%, respectively. Compared with rectangular beams, the glulam T-beams have greater improvements in bearing capacity, stiffness, and ductility coefficient.

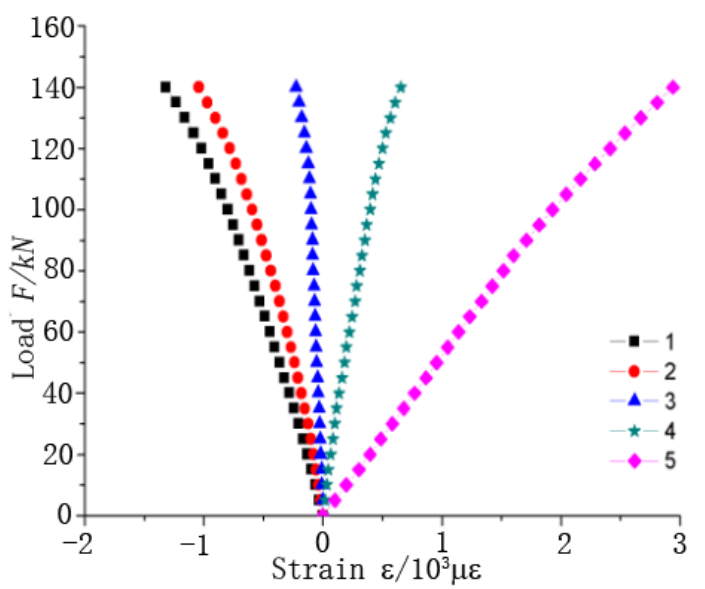

(a) A1

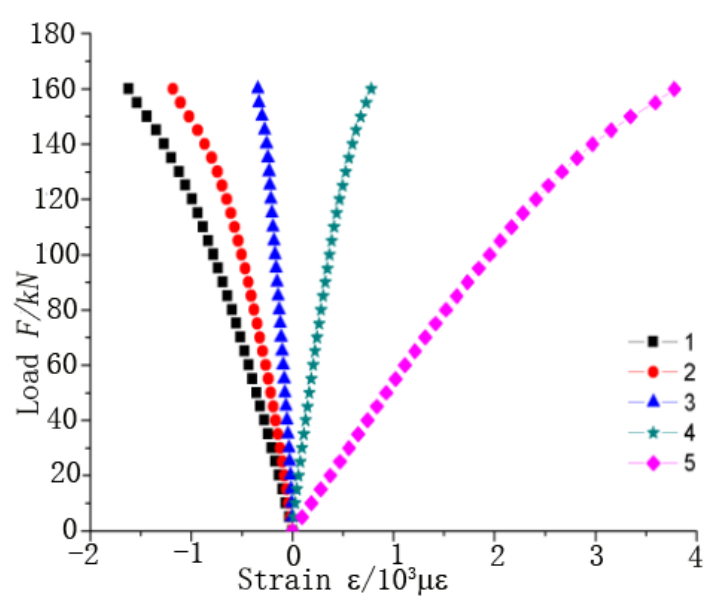

(b) A2 




(c) B1

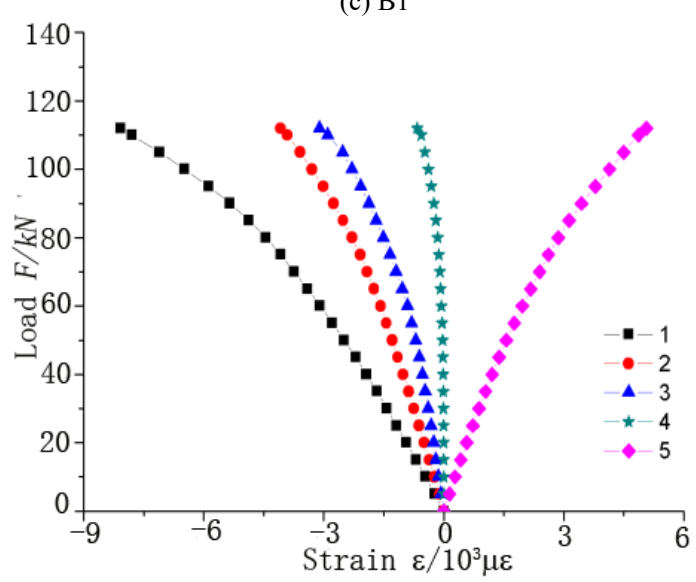

(d) B2

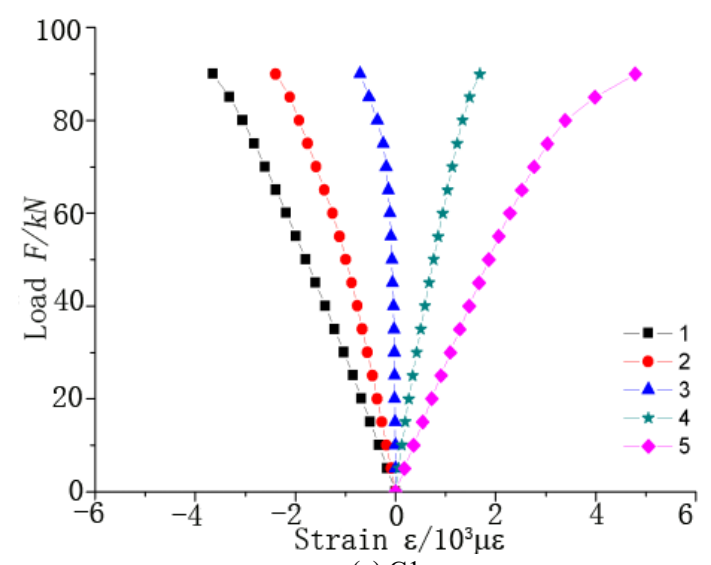

(e) $\mathrm{C} 1$

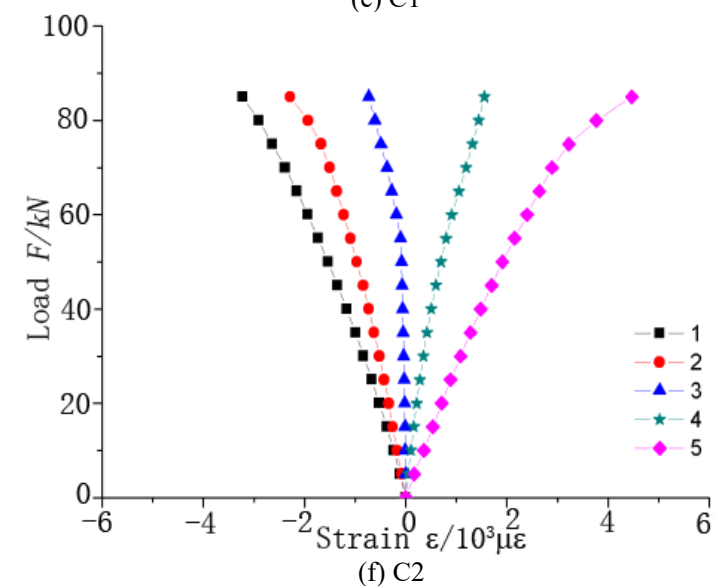

Fig. 8. Test load-strain curve of each specimen.

Table. 4. Mechanical index test results

\begin{tabular}{c|c|c|c|c|c|c|c}
\hline Specimen & $\begin{array}{c}\text { Yield load } \\
P_{y} /(\mathbf{k N})\end{array}$ & $\begin{array}{c}\text { Yield } \\
\text { displacement } \\
D_{y} /(\mathbf{m m})\end{array}$ & $\begin{array}{c}\text { Cracking load } \\
P_{c} /(\mathbf{k N})\end{array}$ & $\begin{array}{c}\text { Ultimate load } \\
P_{u} /(\mathbf{k N})\end{array}$ & $\begin{array}{c}\text { Ultimate } \\
\text { displacement } \\
D_{u} /(\mathbf{m m})\end{array}$ & $\begin{array}{c}\text { Ductility } \\
\text { factor } \\
\mu=D_{u} / D_{y}\end{array}$ & $\begin{array}{c}\text { Initial bending } \\
\text { stiffness }\left(\mathrm{N} \cdot \mathrm{mm}^{2}\right)\end{array}$ \\
\hline $\mathrm{A} 1$ & 110 & 8.01 & 110 & 140 & 17.78 & 2.22 & $2.58 \times 10^{12}$ \\
$\mathrm{~A} 2$ & 110 & 8.57 & 120 & 160 & 28.05 & 3.27 & $2.42 \times 10^{12}$ \\
$\mathrm{~B} 1$ & 70 & 11.90 & 95 & 120 & 34.04 & 2.86 & $1.11 \times 10^{12}$ \\
$\mathrm{~B} 2$ & 65 & 11.13 & 90 & 112 & 30.18 & 2.71 & $1.10 \times 10^{12}$ \\
$\mathrm{C} 1$ & 60 & 12.65 & 80 & 90 & 28.45 & 2.25 & $8.93 \times 10^{11}$ \\
$\mathrm{C} 2$ & 55 & 10.92 & 75 & 85 & 24.27 & 2.22 & $8.35 \times 10^{11}$ \\
\hline
\end{tabular}

Table 5. Comparison of average values of main mechanical indicators

\begin{tabular}{|c|c|c|c|}
\hline Project & $\begin{array}{c}\text { Ultimate load } \\
P_{u}(\mathbf{k N})\end{array}$ & $\begin{array}{c}\text { Ductility factor } \\
\mu=D_{u} / D_{y}\end{array}$ & $\begin{array}{c}\text { Initial bending stiffness } \\
\left(\mathrm{N} \cdot \mathrm{mm}^{2}\right)\end{array}$ \\
\hline $\bar{a}$ & 150 & 2.745 & $2.5 \times 10^{12}$ \\
\hline $\bar{b}$ & 116 & 2.785 & $1.105 \times 10^{12}$ \\
\hline $\bar{c}$ & 87.5 & 2.235 & $8.64 \times 10^{11}$ \\
\hline$(\bar{a}-\bar{c}) / \bar{c} \quad(\%)$ & 71 & 23 & 189 \\
\hline$(\bar{b}-\bar{c}) / \bar{c} \quad(\%)$ & 33 & 25 & 28 \\
\hline
\end{tabular}

\subsection{Shear strength check results}

According to the average value of the cracking load $P_{c}$ for each group of specimens, the maximum shear stress along the central axis of the cross section is calculated according to Equation (1) (the orthogonal beam is equivalent to a parallel beam), which is the ultimate bending shear stress test value.

The shear strength (theoretical value) of the beam is also calculated according to the Rammer formula shown as Equation (3). Comparison of the results is shown in Table. 6.
The table shows that the limit shear stress test value of Group A (parallel T-beam) differs largely by $19.2 \%$ from the theoretical value of shear strength. This finding indicates that the Rammer formula has a slightly low accuracy in calculating the shear strength of components with large effective shear area, and further research on this issue needs to be conducted. The differences between the experimental and theoretical values of the ultimate shear stress of the Bgroup orthogonal T-beams and C-group rectangular beams (except $\mathrm{C} 1$ ) are $8.0 \%$ and $-5.6 \%$, respectively, which indicates that they are in good agreement. 
Table 6. Comparison of experimental and theoretical values of ultimate bending shear stress of glulam beams

\begin{tabular}{c|c|c|c|c|c|c|c}
\hline Member & $\begin{array}{c}\text { Neutral axis } \\
\text { height } \\
\bar{y} /(\mathbf{m m})\end{array}$ & $\begin{array}{c}\text { Effective shear } \\
\text { area } \\
\mathbf{A} /\left(\mathrm{mm}^{2}\right)\end{array}$ & $\begin{array}{c}\text { Quiet distance } \\
S_{Z} /\left(\mathrm{mm}^{3}\right)\end{array}$ & $\begin{array}{c}\text { Moment of } \\
\text { inertia } \\
I_{Z} /\left(\mathrm{mm}^{4}\right)\end{array}$ & $\begin{array}{c}\text { Shear strength } \\
\text { Theoretical value } \\
\tau_{b} /(\mathbf{M p a})\end{array}$ & $\begin{array}{c}\text { Ultimate shear } \\
\text { stress test value } \\
\tau_{\max } /(\mathbf{M p a})\end{array}$ & $\begin{array}{c}\text { Relative error } \\
\delta /(\%)\end{array}$ \\
\hline Group A & 179.4 & 21750 & $1.20 \times 10^{6}$ & $2.44 \times 10^{8}$ & 3.17 & 3.78 & 19.2 \\
Group B & 129.4 & 20050 & $6.28 \times 10^{5}$ & $1.11 \times 10^{8}$ & 3.23 & 3.49 & 8.0 \\
Group C & 120.0 & 15000 & $5.40 \times 10^{5}$ & $0.85 \times 10^{7}$ & 3.42 & 3.23 & -5.6 \\
\hline
\end{tabular}

\subsection{Shear stress in finite element analysis}

According to the reciprocity theorem of shear stress, $S_{12}$ and $S_{21}$ (that is, the shear stress $\tau_{x y}$ in the $\mathrm{YZ}$ plane in the $\mathrm{Y}$ direction and the shear stress $\tau_{y x}$ in the $\mathrm{X}$ direction in the $\mathrm{XZ}$ plane) are equal to each other when under vertical load. They are also considerably larger than those in other directions. The spatial stress state of the unit body is shown in Fig. 9. Through the finite element simulation analysis, the shear stress $S_{12}$ cloud diagram of the glulam beam under the average value of the test ultimate load is shown in Fig. 10.

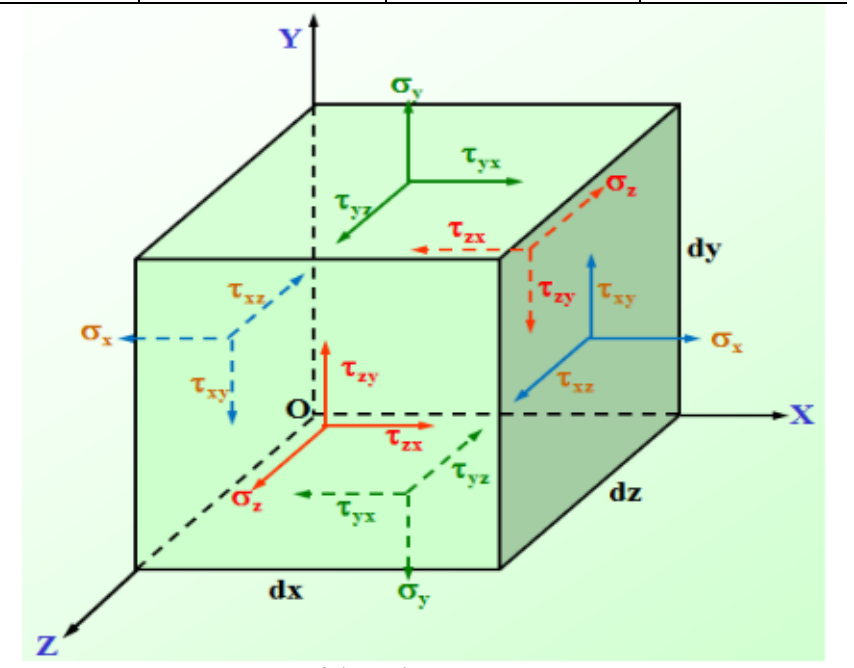

Fig. 9. Space stress state of the unit
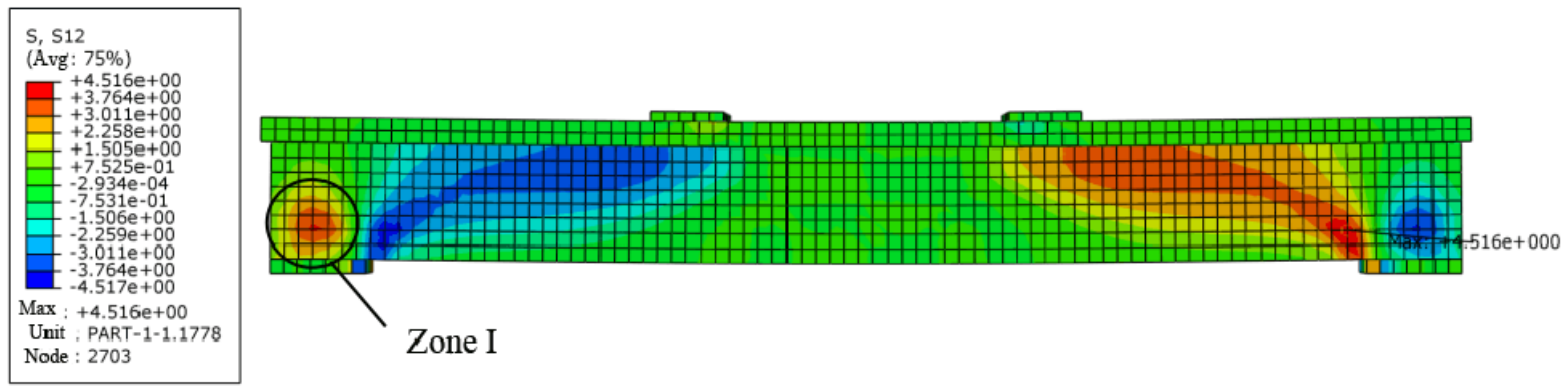

(a)
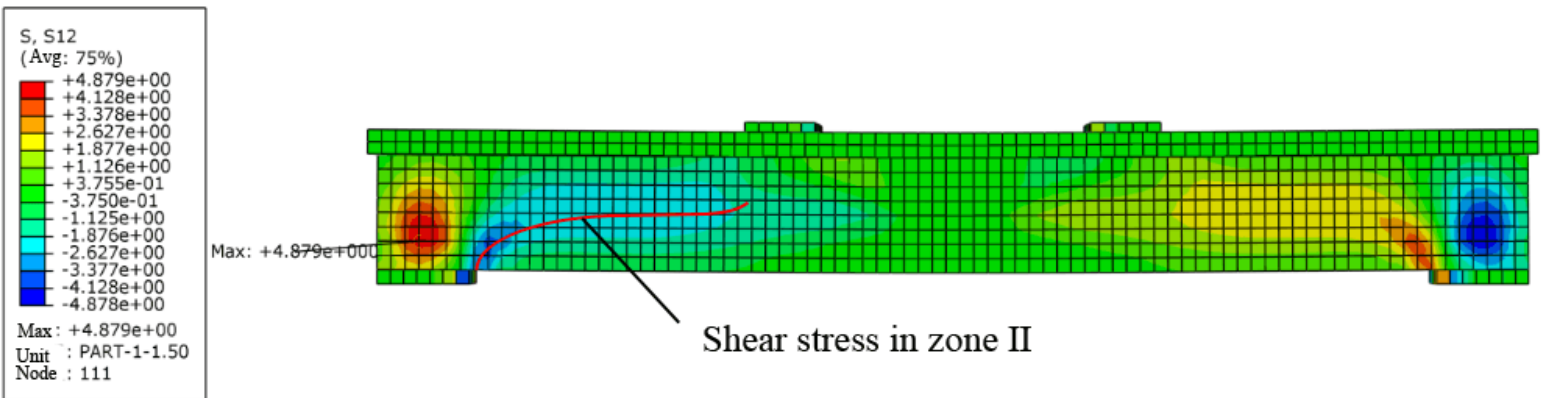

(b)
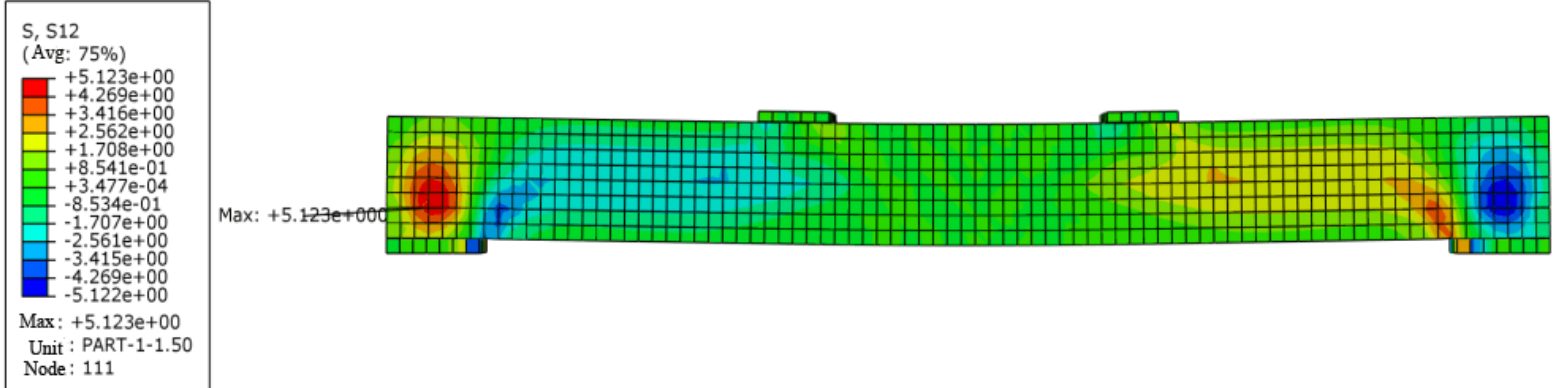

(c)

Fig. 10. Cloud shear stress diagram of glulam beam under ultimate load (unit: Mpa). (a)Parallel beam. (b) Orthogonal beam. (c) Rectangular beam. 
Table. 7. Comparison of the maximum grain shear stress and the grain shear beam shear strength

\begin{tabular}{c|c|c|c|c|c}
\hline Member & $\begin{array}{c}\text { Maximum shear stress } \\
\text { in zone I } \tau_{1 \max } \\
(\mathrm{MPa})\end{array}$ & $\begin{array}{c}\text { Maximum Shear Stress in } \\
\text { Zone II } \tau_{2 \max }(\mathrm{MPa})\end{array}$ & $\begin{array}{c}\text { Down grain shear } \\
\text { strength } \tau_{b} \\
(\mathrm{MPa})\end{array}$ & $\begin{array}{c}\tau_{1 \max }-\tau_{b} \\
(\%)\end{array}$ & $\begin{array}{c}\frac{\tau_{2 \max }-\tau_{b}}{\tau_{b}} \\
(\%)\end{array}$ \\
\hline $\begin{array}{c}\text { Parallel beam } \\
\text { Orthogonal } \\
\text { beam }\end{array}$ & 4.52 & 4.52 & 3.17 & 42.6 & 42.6 \\
$\begin{array}{c}\text { Rectangular } \\
\text { beam }\end{array}$ & 4.88 & 4.13 & 3.23 & 51.1 & 27.9 \\
\hline
\end{tabular}

Fig. 10 shows that, under the limit load, the glulam beam presents the two most unfavorable along-stripe shear stress regions: the first region is above the two supports at the beam end, and the second region is the shear bending section between the beam support and the loading plate. Comparison between the maximum shear stress of two regions along with the shear strength of glulam beams is shown in Table 7 . The shear strength of the wooden beam along the grain is calculated using Equation (3).

Table. 7 shows that the maximum ridge shear stress in the two most unfavorable regions of the three beams exceeds the shear strength by $19 \%-52 \%$, and the test member suffers shear failure in the two regions. The shear stress in Zone I maximizes at the intersection of the plastic neutral axis directly above the support and decreases gradually around the ellipse. Given that the area of the high shear stress area is small, the cracks along the grain shear damage here is short (Fig. 6(b)). The arc from the bottom of the inner beam of the support in Zone II to the neutral axis of the loading section is the main line of maximum shear stress. The arc shows a tendency to extend to the neutral axis across the mid-pure curved section. Therefore, the glulam beam produces a long directional grain shear crack, and the analysis shows that the finite element simulation calculations are consistent with the experimental phenomena.

\section{Conclusions}

A T-beam component was formed to enhance the bending bearing capacity, rigidity, and integrity of glulam beams by gluing wing plates and webs. Chinese Xing'an larch laminates and structural glue were also used to make test pieces for static bending tests and finite element simulation to analyze the bearing capacity, stiffness, and failure mechanism of the component. The following conclusions could be drawn:

(1) Glulam T-beams are subject to shear failure along the grain during bending, which is a brittle failure because the shear strength of the timber along the grain is low. The gluing surface between the wing plate and the web of the Tbeam is undamaged, which indicates that the gluing is reliable, and the overall stress performance of the T-beam is good.

(2) Compared with those of rectangular beams, the bearing capacity, bending stiffness, and ductility coefficient of the parallel T-beams (limit load) are increased by $71 \%, 189 \%$, and $23 \%$, respectively. Compared with those of rectangular beams, the bearing capacity, bending stiffness, and ductility coefficient of the orthogonal T-beams (limit load) are increased by $36 \%, 28 \%$, and $25 \%$, respectively. Overall, glulam T-beams have greater capacity, stiffness, and ductility than rectangular beams.

(3) By considering the principle of equivalent stiffness and using the Rammer formula, the flexural shear strengths of orthogonal T-beams and rectangular beams of glulam differ from the calculated values by $8.0 \%$ and $-5.6 \%$, respectively, which shows a comparatively good conformity. However, the difference between the test and calculated values of the shear strength of glulam parallel T-beams is $19.2 \%$, which indicates that the accuracy of the Rammer formula for calculating the shear strength of members with a large effective shear area is slightly lower. Further study is needed to address this problem.

(4) The finite element simulation analysis and test results of glulam beams agree well with each other.

In this study, experimental and analytical works on the flexural bearing capacity of glulam T-beams were conducted to reveal the characteristics and mechanism of shear failure of T-beams mainly along the grain. We find that the bearing capacity, stiffness, and ductility of the proposed T-beam are better than those of rectangular beams. Thus, a certain reference can be provided for the engineering design of glulam beam bridges. However, the number of test specimens is small, and the test data are insufficient. Therefore, in future research, the number of test specimens should be increased, and the test analysis should be continued. The future research should also address the highprecision calculation of shear strength that is suitable for larger-size glulam T-beams. The influence of parameters, such as high-span and shear-span ratios, on the mechanical properties of glulam T-beams, should also be considered.

\section{Acknowledgements}

This work was supported by the International S\&T Cooperation Program of China (Grant No.2014DFA53120) and the Special Research Program for Public-welfare Forestry of China (Grant No.201304504-3).

This is an Open Access article distributed under the terms of the Creative Commons Attribution License

\section{References}

1. Liu, W. Q., Yang, H. F., "Research Progress of Modern Wood Structures". Journal of Building Structures, 40 (02), 2019, pp. 1643.
2. Wang, J. J., Yang, T., Zhang, X. S., "Static and Stability Analysis of Glulam Continuous Beam Corridor Bridge". Journal of Central South University of Forestry and Technology, 38(07), 2018, pp. 103-109+ 122 . 
3. Gao, J., Dong, W. W., Huang, S. Y., Zhong, Y., Ren, H. Q., "Research progress on influencing factors of nail joint performance in wooden structures". Forest Products Industry, 43(04), 2016, pp. 7-11.

4. Andrew, J. B., "Corrosion of nails in CCA-and ACA-treated wood in two environments". Forest Products Journal, 42(9), 1992, pp. 39-41.

5. Hiroshi, Y., Toshifumi F., "Shear strengths of wood measured by various short beam shear test methods". Wood Science and Technology, 37(3), 2003, pp. 189-197.

6. Roberto, T., Maria, A. P., Maurizio, P., "Ductile design of gluedlaminated timber beams". Practice Periodical on Structural Design and Construction, 14(3), 2009, pp. 113-122.

7. Rammer, D. R., Soltis, L. A., "Experimental shear strength of Glulam-laminated beams". In: Forest Products Laboratory, Research Paper: FPL-RP-527, Madison WI, USA: USDA, 1994, pp. 1-38

8. Cao, L., Zhang, Z. F., Zeng, D., He, G. J., "Study on fatigue properties of larch beams". Journal of Building Structures, 37(10), 2016, pp. 27-35.

9. Zhou, J. L., Feng, X., "Experimental study on mechanical properties of larch glued wood". Journal of Central South University of Forestry and Technology, 36(8), 2016, pp. 125-130.

10. Klapalek, P., Melzerpva, L., "Effect of distribution of Knots on the strength of the glued laminated timber beam". Applied Mechanics and materials, 732, 2015, pp. 365-368.

11. Danielsson, H., Serrano, E., "Cross laminated timber at in-plane beam loading-Prediction of shear stresses in crossing areas". Engineering Structures, 171, 2018, pp. 921-927.

12. Sikora, K. S., McPolin, D. O., Harte, A. M., "Effects of the thickness of cross-laminated timber (CLT) panels made from Irish Sitka spruce on mechanical performance in bending and shear". Construction and Building Materials, 116, 2016, pp. 141-150.
13. Lu, Y., Xie, W. B., Wang, Z., "Shear Stress and Interlaminar Shear Strength Tests of Cross-laminated Timber Beams". Bioresources, 13(3), 2018, pp. 5343-5359.

14. Gong, Y. C., Wu, G. F., Xu, J. H., Ren, H.Q., "Study on flexural properties of Japanese larch orthogonal glulam". Journal of Northwest $A \&$ \& University (Natural Science Edition), 46(11), 2018, pp. 1-6.

15. Julio S., Bruno, P. P., Nilson, T. M., "Mechanical performance of glued-laminated timber beams symmetrically reinforced with steel bars". Composite structures, 150, 2016, pp. 200-207.

16. Yang, X. H., Xue, W., Guo, N., "Bending resistance of steel plate reinforced glulam beams". Journal of Jilin University (Engineering \& Technology Edition), 47(02), 2017, pp. 468-477.

17. Zhang, J., Wang, W. C., Chou, R. G., Shen, H., Xu, Q. F., Gao, S., "Experimental study on short-term bending performance of prestressed glulam beams in vivo". Journal of Civil Engineering, 52 (05), 2019, pp. 23-34.

18. Ewa, S., Maciej, S., Lukasz, P., "A Numerical Analysis of the Resistance and Stiffness of the Timber and Concrete Composite Beam". Civil And Environment Engineering Reports, 15(4), 2015, pp. 139-150.

19. Chen, Q., Lang, J. K., Wang, J. J., "Flexural Properties of BambooLog Composite Beam". Journal of Engineering Science and Technology Review, 11(3), 2018, pp. 104-112.

20. McConnell, E., McPolin, D., Taylor, S., "Post-tensioning of glulam timber with steel tendons". Construction and Building Materials, 73, 2014, pp. 426-433.

21. Yahyaei-Moayyed, M., Taheri, F., "Experimental and computational investigations into creep response of AFRP reinforced timber beams". Composite Structures, 93, 2011, pp. 616-628.

22. Long, W. G., Yang, X. B., “Wood Structure Design Manual (Third Edition)". Beijing: China Construction Industry Press, China, 2005, pp. 16-18. 